\title{
Bioequivalence of Ultra Rapid Lispro (URLi) U100 and U200 Formulations in Healthy Subjects
}

Helle Linnebjerg • Elizabeth Smith LaBell • Mary Anne Dellva •

David E. Coutant $\cdot$ Jennifer Leohr

Received: April 30, 2020 / Published online: June 13, 2020

(C) The Author(s) 2020

\section{ABSTRACT}

Introduction: Ultra rapid lispro (URLi) is a novel insulin lispro formulation that was developed to more closely match physiological insulin secretion. The aims of this study were to demonstrate the bioequivalence (BE) of a concentrated formulation (U200) of URLi to the U100 formulation of URLi after subcutaneous (SC) administration and to evaluate the glucodynamics (GD) of these formulations.

Methods: This phase 1, randomized, two-sequence, four-period, double-blind, replicate crossover study was conducted in 68 healthy subjects. At each dosing visit, subjects received a 15-U SC dose of either U100 URLi or U200 URLi followed by a 10-h euglycemic clamp procedure. Serum insulin lispro and blood glucose concentrations were measured, and the glucose infusion rate was continuously adjusted during the clamp to maintain the target blood glucose. Results: Bioequivalence of U200 URLi relative to U100 URLi was demonstrated. The 90\% confidence intervals (CIs) of the ratios of geometric least squares (LS) means for the maximum insulin concentration and total exposure

Digital Features To view digital features for this article go to: https://doi.org/10.6084/m9.figshare.12349460.

H. Linnebjerg · E. S. LaBell · M. A. Dellva .

D. E. Coutant · J. Leohr $(\bowtie)$

Eli Lilly and Company, Indianapolis, IN, USA

e-mail: leohr_jennifer_k@lilly.com were within the BE limits of 0.80-1.25. Additionally, the $90 \%$ CIs for the ratios of geometric LS means for maximum glucose infusion rate and total glucose infused were within the $\mathrm{BE}$ limits. The early $50 \% t_{\max }$ occurred at approximately the same time for the U100 and U200 URLi formulations, and the insulin exposure within the first $15 \mathrm{~min}$ was similar for both formulations. The tolerability of the two URLi formulations was comparable.

Conclusions: This study demonstrated that the U100 and U200 URLi formulations are bioequivalent. The accelerated insulin absorption observed for the U100 formulation was maintained with the U200 URLi formulation. Further, the GD were similar for both formulations, supporting the ability of individuals to transfer from U100 to U200 URLi in a 1:1 unit conversion.

Trial Registration: NCT03616977.

Keywords: Bioequivalence; Concentrated insulin; Euglycemic glucose clamp; Glucodynamics; Insulin lispro; Pharmacokinetics 


\section{Key Summary Points}

Why carry out this study?

The development of concentrated insulin formulations enables higher insulin doses to be administered in the same injection volume, allowing more insulin units to be included in each injection device.

This study assessed the bioequivalence of a concentrated form of ultra rapid lispro (URLi), U200, to the U100 formulation, and the effects of these formulations on glucodynamics.

\section{What was learned from the study?}

The U100 and U200 formulations of URLi were bioequivalent and exhibited similar effects on glucodynamics, and the accelerated insulin absorption of U100 URLi was maintained in U200 URLi.

This study shows that it is possible for patients with diabetes to transition between U100 and U200 formulations with 1-to-1 unit equivalency, offering an alternative to patients who need higher mealtime insulin doses.

\section{INTRODUCTION}

Control of postprandial glucose excursions is of great importance in achieving target glycosylated hemoglobin $\left(\mathrm{HbA} 1_{c}\right)$ levels in individuals with diabetes. Managing postprandial glucose remains one of the most challenging aspects of diabetes care, contributing to few individuals reaching and maintaining their $\mathrm{HbA}_{\mathrm{c}}$ target range [1]. Many individuals with diabetes rely on rapid-acting insulin therapy to help maintain control of their postprandial glucose. Rapid-acting insulin analogues, such as insulin lispro, aspart, faster-acting aspart, and glulisine, are absorbed more rapidly and have a faster onset of action compared with regular human insulin. Rapid-acting insulin analogues lead to greater reductions in postprandial glucose excursions [2]. However, rapid-acting insulin analogues may not be rapid enough to match carbohydrate absorption, limiting their efficacy in glycemic control and time in range [3]. Thus, there is a need to develop even faster acting insulin preparations that more closely match physiological insulin secretion and thereby maintain individual glucose concentrations in the target range [3].

The correlation between obesity and insulin resistance has led to an increase in insulin requirements for individuals with diabetes. An increasing proportion of individuals with diabetes are considered overweight or obese, so they are likely to require more insulin to manage their condition over the course of the disease $[3,4]$. The development of concentrated insulin formulations enables higher insulin doses to be administered in the same injection volume. This may reduce patient burden by allowing a greater number of units of insulin to be included in each injection device [4]

Insulin lispro (Humalog ${ }^{\circledR}$ ) is a rapid-acting human insulin analogue that is indicated for the improvement of glycemic control in adults and children with diabetes mellitus and is commercially available in U100 and U200 formulations [5]. The U100 and U200 formulations of insulin lispro are bioequivalent and exhibit similar glucodynamics, facilitating 1:1 unit conversion between formulations [4]. The U200 formulation contains twice the amount of insulin with the same concentrations of the enabling excipients on a volume basis. Ultra rapid lispro (URLi) is a novel insulin lispro formulation containing two locally acting excipients: treprostinil to induce local vasodilation and citrate to increase vascular permeability, thereby accelerating insulin lispro absorption $[6,7]$. URLi has shown accelerated insulin lispro absorption, with a corresponding faster onset of insulin action compared with Humalog in healthy volunteers and individuals with type 1 and type 2 diabetes (T1D and T2D) [8-11]. Initial disclosures of phase 3 studies demonstrated the superiority of URLi to Humalog in controlling postprandial glucose excursions in individuals with T1D and T2D $[12,13]$. 
The aims of the present study were to demonstrate the bioequivalence (BE) of a concentrated form (U200) of URLi to the U100 formulation of URLi after subcutaneous (SC) administration and to evaluate the glucodynamics (GD) of these formulations.

\section{METHODS}

\section{Study Design}

This phase 1, investigator- and subject-blind, two-sequence, four-period, randomized, replicated-crossover, 10-h euglycemic clamp study evaluated the pharmacokinetics (PK) and GD of the U100 and U200 formulations of URLi in healthy subjects. The study was conducted at one site (Lilly Centre for Clinical Pharmacology Pte Ltd, Singapore). The study protocol was approved by the National Healthcare Group Domain Specific Review Board, Singapore, and conducted in accordance with the Declaration of Helsinki and Good Clinical Practice guidelines. All subjects provided written informed consent before participating in the study. The study is registered at www.clinicaltrials.gov (NCT03616977).

An overview of the study design is provided in Fig. 1. Subjects were randomized to one of two treatment sequences. The study included a screening period ( $\leq 28$ days) followed by four inpatient treatment periods and $\mathrm{a} \geq 14$-day follow-up period. At least three days of washout occurred between each treatment period.

\section{Subject Eligibility}

Males and females who were considered overtly healthy based on medical history, were aged between 21 and 70 years of age, and had a body weight of $\geq 45 \mathrm{~kg}$ and a body mass index (BMI) of $18-30 \mathrm{~kg} / \mathrm{m}^{2}$ were eligible for the study.

\section{Treatment Administration}

Subjects were randomized to receive a single 15-U SC dose of the study drug (U200 URLi formulation or U100 URLi formulation; Eli Lilly, Indianapolis, United States) per period. The replicated crossover design allowed each formulation to be assessed twice over the four study periods. URLi formulations were administered subcutaneously into alternate abdominal quadrants.

\section{Euglycemic Clamp}

At each dosing visit, subjects fasted for at least $8 \mathrm{~h}$ prior to URLi administration. Following administration, subjects underwent a manual euglycemic clamp procedure for up to $10 \mathrm{~h}$. Baseline blood glucose was calculated for each subject as the mean of blood glucose concentrations at 10,20, and $30 \mathrm{~min}$ prior to study drug administration. Following drug administration, onset of insulin action was defined as when blood glucose dropped by $5 \mathrm{mg} / \mathrm{dL}$ $(0.3 \mathrm{mmol} / \mathrm{L})$ below the subject's fasting baseline, which was set as their target blood glucose level for the euglycemic glucose clamp procedure. The clamp procedure was not performed

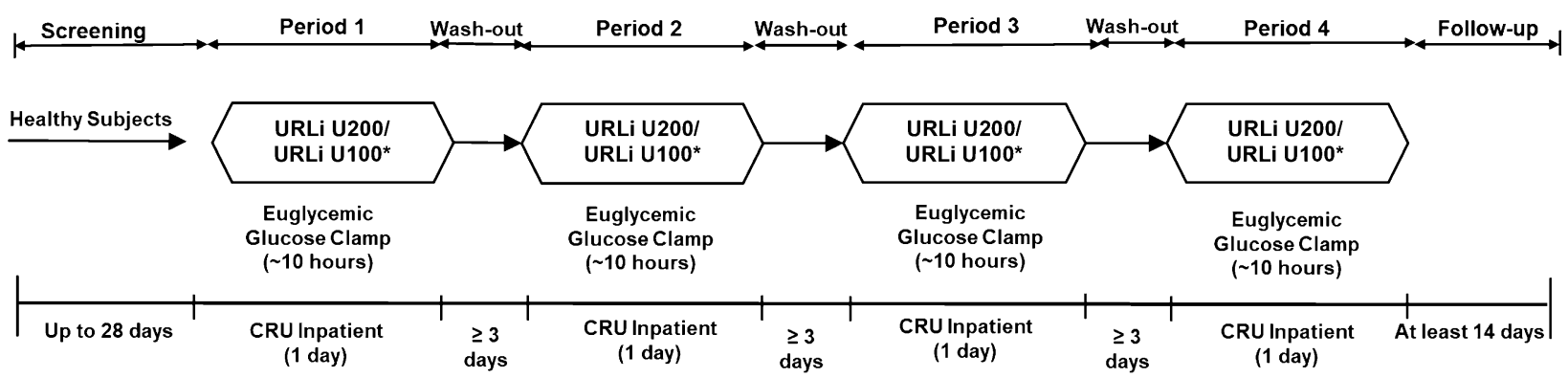

Fig. 1 Study design. $C R U$ clinical research unit, $U R L i$ ultra rapid lispro. *Denotes a single 15-U dose of URLi U100 or U200 administered as a subcutaneous injection to the abdomen 
in subjects with baseline blood glucose targets $\leq 63 \mathrm{mg} / \mathrm{dL}(3.5 \mathrm{mmol} / \mathrm{L})$. Following the onset of insulin action, the glucose infusion rate (GIR) was adjusted manually to maintain the predetermined target blood concentration for each individual subject. Blood glucose was maintained at the target by variable infusion of intravenous 20\% D-glucose (dextrose) solution. The GIR was recorded throughout the clamp procedure and reflected the activity of the administered dose of insulin. Blood samples were collected every $2.5 \mathrm{~min}$ for the first $30 \mathrm{~min}$, every $5 \mathrm{~min}$ for $30-120 \mathrm{~min}$, every $10 \mathrm{~min}$ for $120-480 \mathrm{~min}$, and every $20 \mathrm{~min}$ for 480-600 min.

Glucose levels were measured using glucose analyzers (YSI STAT Plus Glucose and Lactate Analyzer, YSI Inc., Yellow Springs, OH, USA). The clamp was discontinued if the GIR fell to 0 for at least $30 \mathrm{~min}$.

\section{Assessments and Data Analysis}

\section{Bioanalytical Methods}

Free serum insulin lispro was analyzed using a validated enzyme-linked immunosorbent assay (ELISA) that was specific to insulin lispro and had no cross-reactivity with endogenous insulin. Blood samples for insulin lispro PK analysis were taken every $5 \mathrm{~min}$ during the first hour postdose, at 70, 90, 120, 150, and $180 \mathrm{~min}$, and every hour thereafter up to $10 \mathrm{~h}$.

The lower limit of quantitation was $50.0 \mathrm{pg} /$ $\mathrm{mL}(8.61 \mathrm{pM})$ and the interassay accuracy (\% relative error) and interassay precision (\% relative standard deviation) were $\leq 12 \%$. Quantification of insulin lispro was not affected by the presence of lipemic serum, hemolyzed serum, treprostinil (1 ng/mL), or human insulin (10 ng/ $\mathrm{mL})$.

\section{Pharmacokinetics}

Subjects who completed at least one period and had measurable insulin lispro concentrations were included in the PK analysis dataset. Free serum insulin lispro PK parameters were calculated by non-compartmental methods using Phoenix $^{\circledR}$ version 8.0 and S PLUS ${ }^{\circledR}$ version 8.2.
Overall insulin lispro exposure was determined by calculating the area under the concentration-time curve (AUC) from time 0 to infinity $\left(\mathrm{AUC}_{0-\infty}\right)$, the AUC from time 0 to $t_{\text {last }}$, where $t_{\text {last }}$ is the last time point with a measurable concentration $\left(\mathrm{AUC}_{\mathrm{O} \text {-tlast }}\right)$, and the maximum observed drug concentration $\left(C_{\text {max }}\right)$. Early insulin lispro exposure was characterized by the time to early half-maximal drug concentration (early $50 \% t_{\max }$ ), the AUC from time 0 to $15 \mathrm{~min}$ postdose $\left(\mathrm{AUC}_{0-15 \mathrm{~min}}\right)$, and the $\mathrm{AUC}$ from time 0 to 30 min postdose $\left(\mathrm{AUC}_{0-30 \mathrm{~min}}\right)$.

\section{Glucodynamics}

GD were derived from the GIR during the glucose clamp procedure. All subjects who completed at least one clamp procedure were included in the analysis. A locally weighted scatterplot smoothing (LOESS) function with a span of 0.2 was applied to all individual GIR versus time profiles in each treatment group and/or period. GD analyses were conducted using Phoenix ${ }^{\circledR}$ version 6.4 or higher and $\mathrm{S}$ PLUS $^{\circledR}$ version 8.2. The fitted data for each subject were used to calculate the GD parameters except for the time to onset of insulin action ( $\left.T_{\text {onset }}\right)$, which was based on the raw GIR data. Total insulin action was determined from the maximum GIR $\left(R_{\max }\right)$ and the total amount of glucose infused over the duration of the clamp $\left(G_{\text {tot }}\right)$. Early insulin action endpoints were characterized by $T_{\text {onset }}$, time to half-maximal GIR before time to maximal GIR (early $50 \%$ $\left.t R_{\max }\right)$, and the total amounts of glucose infused over the first $30 \mathrm{~min}\left(G_{\text {tot }} 0-30 \mathrm{~min}\right)$ and first $1 \mathrm{~h}$ $\left(G_{\text {tot } 0-1 \mathrm{~h}}\right)$.

\section{Tolerability and Safety}

Safety and tolerability assessment included adverse events, injection-site reactions, clinical laboratory parameters, vital signs, and hypoglycemic events.

\section{Statistical Analysis}

A sample size of 58 subjects was estimated to provide at least $95 \%$ and $90 \%$ power to demonstrate $\mathrm{BE}$ of the $\mathrm{PK}$ parameters and the GD parameters, respectively. The calculations were based on within-subject variability 
estimated using data from a prior URLi study, assuming a difference of up to $5 \%$ in the geometric least squares (LS) mean between formulations. PK parameters $\left(\mathrm{AUC}_{0 \text {-tlast }}, \mathrm{AUC}_{0-\infty}\right.$, and $C_{\text {max }}$ ) were compared between formulations by analyzing log-transformed estimates using a repeated-measures linear mixed-effects model with treatment, sequence, and period as fixed effects and subject as a random effect. The difference in LS means and the corresponding twosided $90 \%$ confidence intervals (CIs) for the treatment difference were estimated and backtransformed from the log scale to provide estimates of the ratio of geometric LS means and the $90 \%$ CI for the ratio of the LS means, in accordance with the FDA-recommended BE analysis methodology [14, 15]. BE was concluded if the two-sided $90 \%$ CI was within the $0.80-1.25$ interval.

Additional $\mathrm{PK}$ parameters $\left(\mathrm{AUC}_{0-15}\right.$ and AUC $\left._{0-30}\right)$ and GD parameters $\left(G_{\mathrm{tot}}, R_{\max }\right.$, and $G_{\text {tot0-1 h }}$ ) were analyzed using the same approach. As $G_{\text {tot0-30 min }}$ had zero values, the estimates without log transformation were used for that analysis. The LS means, treatment differences in LS means, and the corresponding $90 \%$ CIs for the treatment differences were estimated from the model. The treatment ratios and $90 \%$ CIs for the ratios were calculated using Fieller's theorem. The within- and betweensubject variability of both treatments were estimated directly from the repeated-measures linear mixed-effects model for all PK and GD logtransformed parameters. The PK and GD time parameters were analyzed nonparametrically using the Wilcoxon signed-rank test. SAS ${ }^{\circledR}$ version 9.4 (SAS Institute, NC, USA) was used for the statistical analyses.

\section{RESULTS}

\section{Demographics and Baseline Characteristics}

A total of 68 healthy subjects (65 males and 3 females) were randomly assigned to the treatment and received at least one dose of the study drug, with 65 subjects completing the study. The subjects were between 23 and 66 years of age. Most subjects were Asian (98.5\%), with one subject of multiple races, and $95.6 \%$ were male. Subject weight and BMI ranged from 54.3 to $89.9 \mathrm{~kg}$ and from 19.1 to $29.7 \mathrm{~kg} / \mathrm{m}^{2}$, respectively, with mean values of $72.52 \mathrm{~kg}$ and $24.39 \mathrm{~kg} / \mathrm{m}^{2}$ respectively.

A total of three subjects discontinued from the study after period 2, with two subjects discontinuing due to adverse events related to study procedures and one subject withdrawing due to a family emergency.

\section{Pharmacokinetics}

Administration of $15 \mathrm{U}$ of the U100 URLi formulation and the U200 URLi formulation resulted in similar insulin lispro concentration versus time profiles (Fig. 2a). The similarity of the insulin lispro PK profiles obtained using the two different formulations was confirmed by the ratios of the geometric LS means for U200 URLi compared with U100 URLi and the 90\% CIs for the ratios of $\mathrm{AUC}_{0 \text {-tlast, }} \mathrm{AUC}_{0-\infty}$, and $C_{\max }$ (Table 1). The ratios of U200 to U100 were 1.01 for $\mathrm{AUC}_{0 \text {-tlast }}$ and $\mathrm{AUC}_{0-\infty}$ and 0.971 for $\mathrm{C}_{\max }$, and the $90 \%$ CIs for the ratios were within the BE limits (0.80-1.25).

\section{Glucodynamics}

Administration of 15-U doses of the U200 and U100 URLi formulations resulted in similar GIR versus time profiles (Fig. 2b) and estimates of GD parameters. The similarity of the GD profiles was confirmed using the U200/U100 ratios of geometric LS means for $G_{\text {tot }}$ and $R_{\max }$ (Table 1). The ratio of geometric LS means was 1.05 for $G_{\mathrm{tot}}$ and 1.03 for $R_{\max }$, and the $90 \%$ CIs were within the BE limits of $0.80-1.25$.

The blood glucose concentrations during the euglycemic clamp were maintained at the predefined target throughout the procedure, and the mean glucose profiles were similar for the U100 and U200 URLi formulations (Fig. 3).

\section{Early Insulin Lispro Exposure and Insulin Action}

The insulin lispro concentration-time profiles for the U100 and U200 formulations overlapped 
A

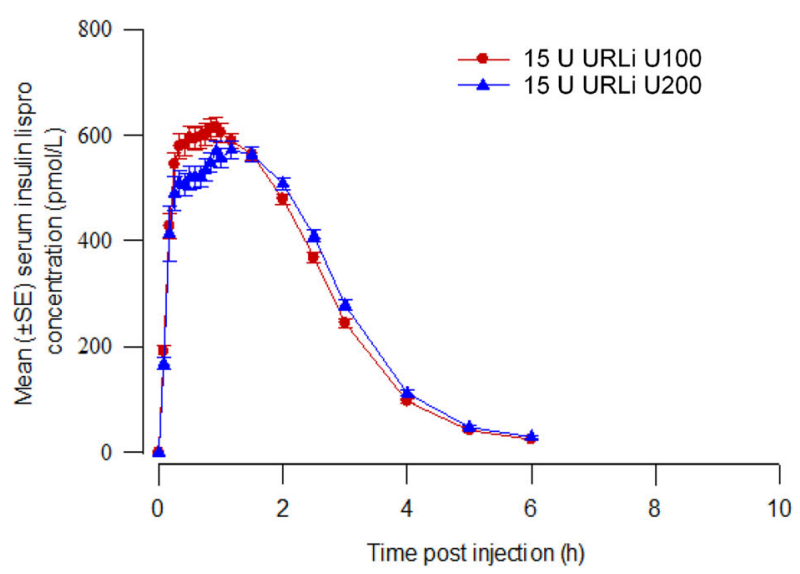

Fig. 2 Linear arithmetic mean serum insulin lispro concentration $( \pm \mathrm{SE}$ ) versus time profiles (a) and mean LOESS fits of weight-normalized glucose infusion rate versus time profiles (b). GIR glucose infusion rate, LOESS

\section{B}

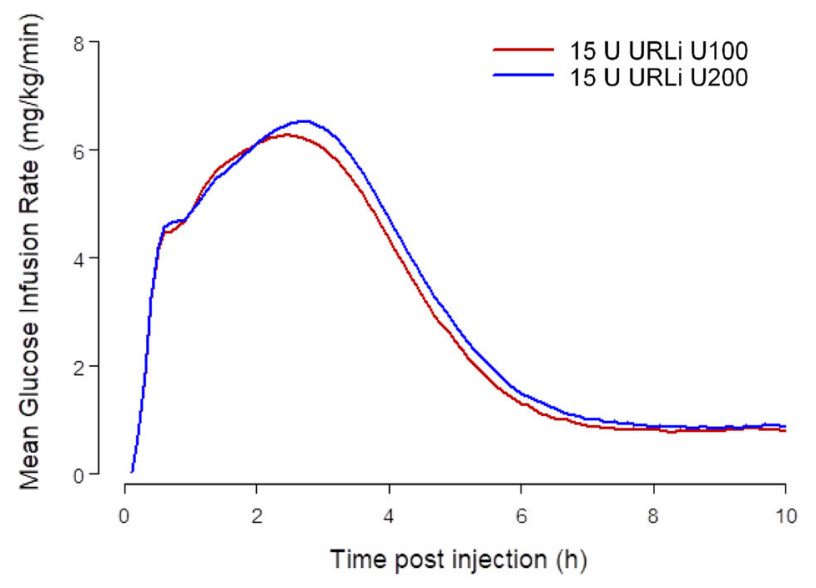

locally weighted scatterplot smoothing, $S E$ standard error, URLi U100 ultra rapid lispro $100 \mathrm{U} / \mathrm{mL}$, URLi U200 ultra rapid lispro $200 \mathrm{U} / \mathrm{mL}$

Table 1 Primary pharmacokinetic and glucodynamic parameters

\begin{tabular}{llllr}
\hline & URLi U100 $(N=68)$ & URLi U200 $(N=68)$ & Ratio of LS means & 90\% CI \\
\hline PK parameters & & & & \\
$\mathrm{AUC}_{0 \text {-tlast }}(\mathrm{pmol} \mathrm{h} / \mathrm{L})$ & 1673 & 1689 & 1.01 & $0.960,1.06$ \\
$\mathrm{AUC}_{0-\infty}(\mathrm{pmol} \mathrm{h} / \mathrm{L})$ & 1688 & 1704 & 1.01 & $0.961,1.06$ \\
$C_{\text {max }}(\mathrm{pmol} / \mathrm{L})$ & 678 & 659 & 0.971 & $0.881,1.07$ \\
$\mathrm{GD}$ parameters & & & 1.05 & $0.94,1.18$ \\
$G_{\text {tot }}(\mathrm{mg} / \mathrm{kg})$ & 1528.98 & 1613.05 & 1.03 & $0.91,1.15$ \\
$R_{\text {max }}(\mathrm{mg} / \mathrm{kg} / \mathrm{min})$ & 6.38 & 6.56 & & \\
\hline
\end{tabular}

Values reported as geometric least squares means

$A U C_{0-\text { tlast }}$ area under the concentration versus time curve from time zero to the last time point with a measurable concentration, $A U C_{O-\infty}$ area under the curve from zero to infinity, $C I$ confidence interval, $C_{\max }$ maximum observed drug concentration, $G D$ glucodynamics, $G_{t o t}$ total glucose infused throughout the clamp, normalized by weight, $h$ hours, $L S$ least squares, $N$ number of subjects, $P K$ pharmacokinetics, $R_{\max }$ maximum glucose infusion rate normalized by weight, $U R L i$ U100 ultra rapid lispro $100 \mathrm{U} / \mathrm{mL}$, URLi U200 ultra rapid lispro $200 \mathrm{U} / \mathrm{mL}$

during the first $30 \mathrm{~min}$ following dosing (Fig. 2a). PK analyses of early insulin lispro PK are presented in Table 2 . The early $50 \% t_{\max }$ occurred at $9.38 \mathrm{~min}$ and $10.22 \mathrm{~min}$ following the administration of U100 and U200 URLi, respectively. The early insulin lispro exposures $\left(\mathrm{AUC}_{0-15 \mathrm{~min}}\right.$ and $\left.\mathrm{AUC}_{0-30 \mathrm{~min}}\right)$ were similar for the U100 and U200 formulations (Table 2).
Early insulin action was also similar for the formulations. The onset of insulin action $\left(T_{\text {on- }}\right.$ set) occurred at appropriately the same time (21.3 vs 21.9 min postinjection, respectively) for the U100 and U200 URLi formulations. Furthermore, the early $50 \% t R_{\max }$ occurred 27 min after injection for both formulations. Correspondingly, the amounts of glucose 


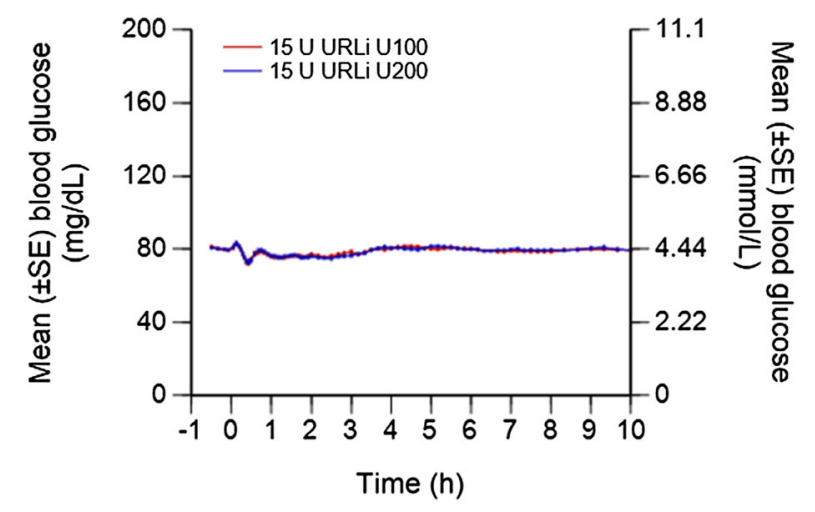

Fig. 3 Arithmetic mean ( \pm SE) blood glucose concentration profiles during euglycemic clamps following the injection of $15 \mathrm{U}$ of the U100 and U200 URLi formulations. SE standard error, URLi U100 ultra rapid lispro $100 \mathrm{U} / \mathrm{mL}, U R L i$ U200 ultra rapid lispro $200 \mathrm{U} / \mathrm{mL}$ infused in the first $30 \mathrm{~min}\left(G_{\text {toto-30 min }}\right)$ and in the first hour $\left(G_{\text {tot0-1 h }}\right)$ of the clamp with the U200 formulation were similar to those obtained with the U100 formulation (Table 2).

\section{Variability of Pharmacokinetic and Glucodynamic Parameters}

Estimates of the intra-subject variability of the PK parameters were similar for both formulations $\left(\leq 9.51 \%\right.$ and $\leq 9.63 \%$ for $\mathrm{AUC}_{0-\infty}$ and $\left.\mathrm{AUC}_{0 \text {-tlast }}\right)$. The intra-subject variability of $C_{\max }$ for U100 was lower than that for U200 (16.3\% versus $25.4 \%$ ). Estimates of inter-subject variability were similar for the U100 and U200 formulations of URLi for all PK parameters (Table 3).

Table 2 Pharmacokinetic and glucodynamic parameters of faster insulin absorption/action

\begin{tabular}{|c|c|c|c|c|}
\hline & $\begin{array}{l}\text { URLi U100 } \\
(N=68)\end{array}$ & $\begin{array}{l}\text { URLi U200 } \\
(N=68)\end{array}$ & $\begin{array}{l}\text { Ratio of or difference in LS } \\
\text { means }\end{array}$ & $\begin{array}{l}90 \% \text { CI (ratio or } \\
\text { difference) }\end{array}$ \\
\hline \multicolumn{5}{|c|}{ Early exposure PK parameters } \\
\hline $\begin{array}{l}\mathrm{AUC}_{0-15} \min \\
(\mathrm{pmol} . \mathrm{h} / \mathrm{L})\end{array}$ & $64.5^{\mathrm{a}}$ & $56.6^{\mathrm{a}}$ & 0.878 & $0.768,1.00$ \\
\hline $\begin{array}{l}\mathrm{AUC}_{0-30 \mathrm{~min}} \\
(\mathrm{pmol} . \mathrm{h} / \mathrm{L})\end{array}$ & $198^{\mathrm{a}}$ & $170^{\mathrm{a}}$ & 0.857 & $0.761,0.965$ \\
\hline $\begin{array}{l}\text { Early } 50 \% t_{\max } \\
(\min )\end{array}$ & $9.38^{\mathrm{b}}$ & $10.22^{\mathrm{b}}$ & $1.15^{\mathrm{c}}$ & $0.61,1.86$ \\
\hline \multicolumn{5}{|c|}{ Early insulin action GD parameters } \\
\hline$G_{\text {tot } 0-30 \min }(\mathrm{mg} / \mathrm{kg})$ & $46.82^{a}$ & $47.10^{\mathrm{a}}$ & 1.01 & $0.92,1.09$ \\
\hline$G_{\text {tot } 0-1 \mathrm{~h}}(\mathrm{mg} / \mathrm{kg})$ & $159.33^{\mathrm{a}}$ & $155.30^{\mathrm{a}}$ & 0.97 & $0.83,1.15$ \\
\hline $\begin{array}{l}\text { Early } 50 \% t R_{\max } \\
(\min )\end{array}$ & $27.21^{b}$ & $27.39^{\mathrm{b}}$ & $0.40^{c}$ & $-0.96,1.71$ \\
\hline$T_{\text {onset }}(\min )$ & $21.30^{\mathrm{b}}$ & $21.90^{\mathrm{b}}$ & $0.15^{c}$ & $0.00,1.50$ \\
\hline
\end{tabular}

a Values reported as geometric least squares means

b Median values

c Median of differences

$A U C_{0-15 \text { min }}$ area under the concentration versus time curve from time zero to $15 \mathrm{~min}$ postdose, $A U C_{0-30 \mathrm{~min}}$ area under the concentration versus time curve from time zero to $30 \mathrm{~min}$ postdose, $C I$ confidence interval, GD glucodynamics, early $50 \%$ $t_{\max }$ time to early half-maximal drug concentration, early $50 \% t R_{\max }$ time to half-maximal glucose infusion rate before $t R_{\text {max }}$, $G_{t o t 0-30 \mathrm{~min}}$ total glucose infused from time zero to $30 \mathrm{~min}$ postdose, $G_{t o t 0-1 \mathrm{~h}}$ total glucose infused from time zero to $1 \mathrm{~h}$ postdose, $h$ hours, min minutes, $L S$ least squares, $N$ number of subjects, $P K$ pharmacokinetics, $t_{\max }$ time of maximum observed drug concentration, $t R_{\max }$ time of maximum glucose infusion rate, $T_{\text {onset }}$ time of first positive glucose infusion rate, URLi U100 ultra rapid lispro $100 \mathrm{U} / \mathrm{mL}$, URLi U200 ultra rapid lispro $200 \mathrm{U} / \mathrm{mL}$ 
Table 3 Intra- and inter-subject variability of key pharmacokinetic and glucodynamic parameters when using the U100 and U200 formulations of URLi

\begin{tabular}{|c|c|c|c|c|}
\hline & \multicolumn{2}{|c|}{ Intra-subject variability CV\% (90\% CI) } & \multicolumn{2}{|c|}{ Inter-subject variability $\mathrm{CV} \%(90 \% \mathrm{CI})$} \\
\hline & $\begin{array}{l}\text { URLi U100 } \\
(N=68)\end{array}$ & $\begin{array}{l}\text { URLi U200 } \\
(N=68)\end{array}$ & $\begin{array}{l}\text { URLi U100 } \\
(N=68)\end{array}$ & $\begin{array}{l}\text { URLi U200 } \\
(N=68)\end{array}$ \\
\hline \multicolumn{5}{|l|}{ PK parameters } \\
\hline $\mathrm{AUC}_{0-\infty}(\mathrm{pmol} \mathrm{h} / \mathrm{L})$ & $9.51(8.30,11.2)$ & $8.30(7.25,9.74)$ & $16.5(14.1,20.0)$ & $16.1(13.8,19.3)$ \\
\hline $\begin{array}{l}\mathrm{AUC}_{0 \text {-tlast }}(\mathrm{pmol} \mathrm{h} / \\
\mathrm{L})\end{array}$ & $9.63(8.40,11.3)$ & $8.40(7.34,9.87)$ & $16.7(14.3,20.2)$ & $16.3(14.0,19.6)$ \\
\hline$C_{\max }(\mathrm{pmol} / \mathrm{L})$ & $16.3(14.3,19.2)$ & $25.4(22.2,29.9)$ & $32.7(28.0,39.6)$ & $30.4(25.3,38.7)$ \\
\hline \multicolumn{5}{|l|}{ GD parameters } \\
\hline$G_{\text {tot }}(\mathrm{mg} / \mathrm{kg})$ & $27.32(23.80,32.23)$ & $23.97(20.89,28.26)$ & $36.27(30.29,45.67)$ & $37.42(31.57,46.35)$ \\
\hline$R_{\max }(\mathrm{mg} / \mathrm{kg} / \mathrm{min})$ & $19.02(16.60,22.37)$ & $17.99(15.70,21.14)$ & $39.62(33.82,48.18)$ & $40.98(35.07,49.66)$ \\
\hline
\end{tabular}

$A U C_{O-\text { tlast }}$ area under the concentration versus time curve from time zero to the last point with a measurable concentration, $A U C_{O-\infty}$ area under the curve from zero to infinity, $C I$ confidence interval, $C_{\text {max }}$ maximum observed drug concentration, $G D$ glucodynamics, $G_{t o t}$ total glucose infused throughout the clamp, $b$ hours, $L S$ least squares, min minutes, $N$ number of subjects, $P K$ pharmacokinetics, $R_{\max }$ maximum glucose infusion rate, URLi U100 ultra rapid lispro $100 \mathrm{U} / \mathrm{mL}, U R L i U 200$ ultra rapid lispro $200 \mathrm{U} / \mathrm{mL}$

Both the inter- and intra-subject variability were similar for all GD parameters measured, with similar coefficients of variation recorded for both the U100 and U200 formulations. The intra-subject variability in the GD parameters was similar for both formulations: $27.32 \%$ and $23.97 \%$ for $G_{\text {tot }}$ and $19.02 \%$ and $17.99 \%$ for $R_{\text {max }}$. Likewise, the inter-subject variability in $G_{\text {tot }}$ and $R_{\max }$ with the $\mathrm{U} 200$ formulation was similar to that obtained with the U100 formulation (Table 2).

\section{Safety and Tolerability}

During the study, a total of 140 TEAEs were reported by 49 subjects (72.1\%), and 39 of those (reported by 18 subjects [26.5\%]) were considered to be related to the study treatment (Table 4). All TEAEs were of mild severity, and the frequency of TEAEs was generally comparable following the administration of U100 or U200 URLi formulation. Two subjects discontinued from the study due to mild TEAEs (infusion site pain and cellulitis, respectively) that were not related to the study drug but were considered to be related to the clamp procedure. The most frequent TEAEs reported in more than two subjects are shown in Table 4 . No clinically significant alterations in laboratory values or vital signs were identified, and no cases of hypoglycemia were reported. Both formulations were well tolerated in healthy subjects, with no notable differences in tolerability between the formulations.

\section{DISCUSSION}

This is the first study to demonstrate BE and comparable GD responses between the U200 and U100 URLi formulations. Estimates of interand intra-subject variability were similar for both formulations, and both were well tolerated.

Consistent with regulatory guidance for studies of BE $[14,15]$, the study was conducted in healthy subjects to reduce the pharmacokinetic variability not related to the differences between pharmaceutical products by avoiding underlying disease or concomitant medication 
Table 4 Treatment-emergent adverse events for all causalities (reported by $\geq 2$ subjects)

\begin{tabular}{lll}
\hline TEAE (MedDRA preferred term) & \multicolumn{2}{l}{ Number of adverse events ${ }^{\mathbf{a}}$ (number of subjects with adverse events) } \\
\cline { 2 - 3 } & URLi U100 $(\boldsymbol{N}=\mathbf{6 8})$ & URLi U200 $(\boldsymbol{N}=\mathbf{6 8})$ \\
\hline All & $77(40)$ & $63(29)$ \\
Infusion site swelling $^{\mathrm{b}}$ & $10(10)$ & $10(10)$ \\
Headache & $8(7)$ & $10(7)$ \\
Infusion site pain $^{\mathrm{b}}$ & $4(4)$ & $4(3)$ \\
Catheter site bruise & $4(3)$ & $2(2)$ \\
Nausea & $2(2)$ & $4(3)$ \\
Infusion site bruising & $2(2)$ \\
Catheter site pain & $3(3)$ & $1(1)$ \\
Catheter site swelling & $4(3)$ & - \\
Arthralgia & $5(4)$ & - \\
Dizziness & $5(2)$ & $3(3)$ \\
Vessel puncture site bruise & $1(1)$ & - \\
\hline
\end{tabular}

MedDRA version 21.0

$N$ number of subjects studied, TEAE treatment-emergent adverse events, URLi U100 ultra rapid lispro $100 \mathrm{UmL}, U R L i$ U200 ultra rapid lispro $200 \mathrm{U} / \mathrm{mL}$

a Adverse events with a change in severity are only counted once at the highest severity

b 'TEAE relates to glucose infusion during the clamp procedure

use in patients. Using a euglycemic clamp procedure enabled safe administration of the insulin formulations. Even though BE was established within healthy subjects, it would also be applicable to the target population of individuals with diabetes [16]. Lastly, the implementation of a crossover design was in line with regulatory guidance for BE studies, and allowed subjects to be their own control, thereby increasing the ability to discern differences because of the formulation. The treatment periods were at least 3 days apart to ensure that drug concentrations were below the lower limit of quantification in all subjects at the next period.

A dose of $15 \mathrm{U}$ was selected for this study as it was within the typical dose range of insulin required by individuals with $\mathrm{T} 1 \mathrm{D}$ and $\mathrm{T} 2 \mathrm{D}$ in clinical practice [17-19]. Further, insulin clamp studies often use a fixed insulin dose, as it reduces the PK variability introduced by using weight-based dose calculations [3, 20]. Additionally, a 15-U dose provides measurable PK and GD profiles for both study formulations and is a safe and tolerable dose that can be administered to healthy volunteers during a euglycemic clamp. Given the linear PK of the U100 formulation of URLi, the use of a single dose is acceptable when assessing BE [8]. As the results of this study demonstrated BE of the two URLi formulations, similar findings would be expected with different dose levels.

The accelerated time-action of U100 URLi compared to U100 Humalog has been shown across different dose levels and patient populations [8-10]. Notably, a more concentrated U200 formulation maintained the accelerated insulin lispro absorption and fast insulin action of URLi. The early $50 \% t_{\max }$ occurred at approximately the same time for the U100 and U200 URLi formulations. Both of the early insulin lispro exposures $\left(\mathrm{AUC}_{0-15}\right.$ min and $\mathrm{AUC}_{0-}$ 
$30 \mathrm{~min}$ ) were similar for the U100 and U200 URLi formulations. Importantly, the glucodynamic analysis showed that time to onset of insulin action $\left(T_{\text {onset }}\right)$ was the same for the U100 and U200 URLi formulations. Additionally, the early $50 \% t R_{\max }$ occurred at about 27 min postdose for both formulations. The magnitude of early glucose lowering within the first $30 \mathrm{~min}$ and the first hour were approximately the same. Thus, the benefit of the rapid insulin action of URLi previously seen for the U100 formulation was maintained for the U200 formulation. It is expected that a U200 formulation of URLi will offer an alternative to individuals who require higher mealtime insulin doses by reducing the volume required for injection. In addition, an increase in insulin strength from 100 to $200 \mathrm{U} /$ $\mathrm{mL}$ will double the number of units per insulin pen.

In conclusion, the U100 and U200 formulations of URLi were bioequivalent and demonstrated similar GD responses. U200 URLi maintains the accelerated absorption and onset of action previously observed for the U100 formulation, and data from this study support the ability of individuals with diabetes to transition between formulations with 1-to-1 unit equivalency.

\section{ACKNOWLEDGEMENTS}

The authors would like to thank all study participants.

Funding. This study and the Rapid Service Fee were funded by Eli Lilly and Company.

Medical Writing Assistance. Medical writing assistance was provided by Carwyn Edwards, PhD (Covance) and Kristen Syring, PhD (Eli Lilly and Company). Eli Lilly and Company provided funding for the writing assistance.

Authorship. All named authors meet the International Committee of Medical Journal Editors (ICMJE) criteria for authorship for this article, take responsibility for the integrity of the work as a whole, and have given their approval for this version to be published.

Authorship Contributions. All authors participated in the drafting, critical revision, and approval of the final version of the manuscript. HL and JL were involved in the study design. HL was responsible for medical monitoring. DEC, ESL, and JL conducted data analyses, and MAD conducted the statistical analyses. All authors were involved in interpretation of the study results.

Disclosures. Helle Linnebjerg, Elizabeth Smith LaBell, Mary Anne Dellva, David E. Coutant, and Jennifer Leohr are employees and shareholders of Eli Lilly and Company.

Compliance with Ethics Guidelines. The study protocol was approved by the National Healthcare Group (NHG) Domain Specific Review Board, Singapore, and conducted in accordance with the Declaration of Helsinki and Good Clinical Practice guidelines. All subjects provided written informed consent before participating in the study. The study was registered at www.clinicaltrials.gov (NCT03616977).

Data Availability. The datasets obtained and/or analyzed during the current study are available from the corresponding author on reasonable request.

Open Access. This article is licensed under a Creative Commons Attribution-NonCommercial 4.0 International License, which permits any non-commercial use, sharing, adaptation, distribution and reproduction in any medium or format, as long as you give appropriate credit to the original author(s) and the source, provide a link to the Creative Commons licence, and indicate if changes were made. The images or other third party material in this article are included in the article's Creative Commons licence, unless indicated otherwise in a credit line to the material. If material is not included in the article's Creative Commons licence and your intended use is not permitted by statutory regulation or exceeds the permitted use, you will need to obtain permission directly from the 
copyright holder. To view a copy of this licence, visit http://creativecommons.org/licenses/by$\mathrm{nc} / 4.0 /$.

\section{REFERENCES}

1. Foster NC, Beck RW, Miller KM, et al. State of type 1 diabetes management and outcomes from the T1D exchange in 2016-2018. Diabetes Technol Ther. 2019;21(2):66-72. https://doi.org/10.1089/dia. 2018.0384 .

2. Nicolucci A, Ceriello A, Di Bartolo P, Corcos A, Orsini FM. Rapid-acting insulin analogues versus regular human insulin: a meta-analysis of effects on glycemic control in patients with diabetes. Diabetes Ther. 2020;11(3):573-84. https://doi.org/10.1007/ s13300-019-00732-w.

3. Heinemann L, Beals JM, Malone J, et al. Concentrated insulins: history and critical reappraisal. J Diabetes. 2019;11(4):292-300. https://doi.org/10. 1111/1753-0407.12861.

4. Czech MP. Insulin action and resistance in obesity and type 2 diabetes. Nat Med. 2017;23(7):804-14. https://doi.org/10.1038/nm.4350.

5. Eli Lilly and Company. Humalog (insulin lispro injection, USP [rDNA origin]) for injection. 2013. https://www.accessdata.fda.gov/drugsatfda_docs/ label/2013/020563s115lbl.pdf. Accessed 23 Jan 2020 .

6. Michael MD, Zhang C, Siesky AM, Cox AL, Sperry $\mathrm{AE}$, Hansen RJ, Christe ME, Farmen MW, $\mathrm{Wu} \mathrm{H}$, Paavola CD, Moyers JS. Exploration of the mechanism of accelerated absorption for a novel insulin lispro formulation. Diabetes. 2017;66(Suppl 1): A250.

7. Pratt E, Leohr J, Heilmann C, Johnson J, Landschulz W. Treprostinil causes local vasodilation, is well tolerated, and results in faster absorption of insulin lispro. Diabetes. 2017;66(Suppl 1):A253.

8. Leohr J, Dellva MA, Coutant DE et al. Pharmacokinetics and glucodynamics of ultra rapid lispro (URLi) accelerates insulin lispro absorption and insulin action vs. Humalog (lispro) in patients with type 2 diabetes. A phase 1 randomized, crossover study in T2D. Clin Pharmacokinet. 2020. [e-Pub ahead of print].

9. Linnebjerg $\mathrm{H}$, Zhang $\mathrm{Q}$, LaBell E et al. Pharmacokinetics and glucodynamics of ultra rapid lispro (URLi) versus Humalog ${ }^{\circledR}$ (lispro) in younger adults and elderly patients with type 1 diabetes: a randomised controlled trial. Clin Pharmacokinet. 2020. [e-Pub ahead of print].

10. Linnebjerg $\mathrm{H}$, Klein O, Plum-Moerschel, et al. Pharmacokinetic and glucodynamic responses of ultra-rapid lispro (URLi) vs Humalog (lispro) across a clinically relevant range of subcutaneous doses in healthy subjects. (under review)

11. Shiramoto $M$, Nasu R, Oura $T$, et al. Ultra-rapid lispro results in accelerated insulin lispro absorption and faster early insulin action in comparison with Humalog ${ }^{\circledR}$ in Japanese patients with type 1 diabetes. J Diabetes Investig. 2019. https://doi.org/ 10.1111/jdi.13195.

12. Blevins $\mathrm{T}$, Zhang Q, Frias JP, Jinnouchi H, Chang AM. Randomized double-blind clinical trial comparing ultra rapid lispro with lispro in a basal-bolus regimen in patients with type 2 diabetes: PRONTOT2D. Diabetes Care. (in press).

13. Klaff L, Cao D, Dellva MA, et al. Ultra rapid Lispro (URLi) improves postprandial glucose (PPG) control vs. humalog (lispro) in T1D: PRONTO-T1D study. Diabetes Obes Metab. (in press).

14. Food and Drug Administration. Guidance for industry: Statistical approaches to establishing bioequivalence. 2001. https://www.fda.gov/ downloads/Drugs/.../Guidances/ucm070244.pdf. Accessed 27 Jan 2020.

15. Food and Drug Administration. Guidance for industry: Bioavailability and bioequivalence studies submitted in NDAs or INDs-general considerations-draft guidance. 2014. https://www.fda.gov/ downloads/drugs/guidancecomplianceregulatoryi nformation/guidances/ucm389370.pdf. Accessed 27 Jan 2020.

16. Galgatte UC, Jamdade VR, Aute PP, Chaudhari PD. Study on requirements of bioequivalence for registration of pharmaceutical products in USA. Eur Can Saudi Pharm J. 2014;22(5):391-402. https://doi.org/ 10.1016/j.jsps.2013.05.001.

17. Heller S, Koenen C, Bode B. Comparison of insulin detemir and insulin glargine in a basal-bolus regimen, with insulin aspart as the mealtime insulin, in patients with type 1 diabetes: a 52-week, multinational, randomized, open-label, parallel-group, treat-to-target noninferiority trial. Clin Ther. 2009;31(10):2086-97. https://doi.org/10.1016/j. clinthera.2009.10.006.

18. Herbst $\mathrm{KL}$, Hirsch IB. Insulin strategies for primary care providers. Clin Diabetes. 2002;20(1):11-7. https://doi.org/10.2337/diaclin.20.1.11.

19. Rosenstock J, Ahmann AJ, Colon G, Scism-Bacon J, Jiang $\mathrm{H}$, Martin S. Advancing insulin therapy in 
type 2 diabetes previously treated with glargine plus oral agents: prandial premixed (insulin lispro protamine suspension/lispro) versus basal/bolus (glargine/lispro) therapy. Diabetes Care. 2008;31(1): 20-5. https://doi.org/10.2337/dc07-1122.
20. MannKind Corporation. AFREZZA ${ }^{\circledR}$ (insulin human) inhalation powder: highlights of prescribing information. Brisbane: MannKind Corporation; 2014. 